Resenha

\title{
A Força do Povo: \\ experiência atual e fonte de esperança
}

The Strength of the People: current experience and source of hope

La Fuerza del Pueblo:

experiencia actual y fuente de esperanza

La Force du Peuple:

expérience actuelle et source d'espoir

Obra: A Força do Povo: democracia participativa em Lages

Autores: Marcio Moreira Alves

Cidade: São Paulo

Editora: Brasiliense

Ano: 1980

Páginas: 150

ISBN: 19824150

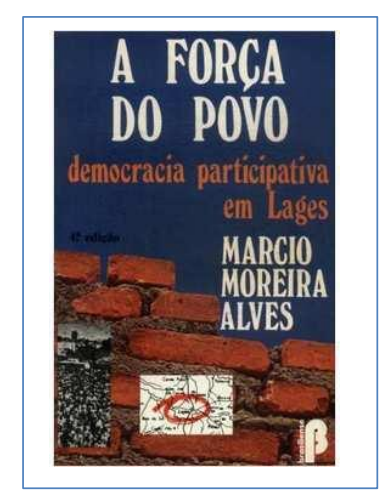

Eduardo de Lima Caldas ${ }^{1}$

\footnotetext{
${ }^{1}$ Graduado em Economia e em Ciências Sociais pela Universidade de São Paulo, São Paulo, SP, Brasil, mestrado em Administração Pública e Governo pela Fundação Getúlio Vargas, São Paulo, SP, Brasil; e mestre e doutor em Ciência Política pela Universidade de São Paulo, São Paulo, São Paulo Brasil. Realizou pós-doutorado no Centre International de Recherches Agronomiques pour le Développement, Montpellier, França. Atualmente é docente no curso de Gestão Ambiental e nos Programas de Pós-Graduação em Ciência Ambiental e de Mudança Social e Participação Política da Universidade de São Paulo, SP, Brasil. 
Em 1980, o jornalista Márcio Moreira Alves escreveu a "A força do povo: democracia participativa em Lages". Então não é um livro novo, tampouco se trata de um relançamento. Ainda assim, merece uma resenha à medida que suas ideias continuam atuais mesmo em contexto muito distinto, os atores com ele envolvidos merecem o apreço das novas gerações de cientistas sociais, e por esses motivos eu considero este livro um clássico.

Antes, porém, de apresentar o livro de Márcio Moreira Alves (1980), faço breves considerações sobre os clássicos em geral. Calvino (19893), elenca 14 definições para os clássicos, dentre as quais:

Definição 3: "Os clássicos são livros que exercem uma influência particular quando se impõem como inesquecíveis e também quando se ocultam nas dobras da memória, mimetizando-se com o inconsciente coletivo ou individual" (Calvino, 1993: 10).

Definição 6: "Um clássico é um livro que nunca terminou de dizer aquilo que tinha para dizer" (Calvino, 1993: 11).

Diferente da leitura de comentadores ou mesmo das resenhas, recomenda-se a leitura do clássico em si. A resenha, nesta medida, serve tanto para recomendar a leitura quanto para incitar o desejo da leitura pela não recomendação.

Calvino (1993) diz que "nunca será demais recomendar a leitura direta dos textos originais, evitando o mais possível bibliografia crítica, comentários, interpretações. A escola e a universidade deveriam servir para fazer entender que nenhum livro que fala de outro livro diz mais sobre o livro em questão" (Calvino, 1993: 12).

Eis, portanto, motivos que justificam a resenha tardia de um livro de quase 40 anos. Trata-se de um clássico!

A primeira vez que tive acesso a esse livro foi em 1986. Trabalhava na Livraria Musicultural, de propriedade dos meus pais, em Suzano (SP) e, além do acesso aos livros, jornais, revistas e discos, tinha acesso também a lançamentos de livros e aos professores, sindicalistas, militantes partidários que frequentavam o ambiente tanto para a compra de livros quanto para organizar partidos, eleições, convenções e ações diversas. Esse livro me foi recomendado pelo então sindicalista Francisco Nunes (Chico Favela) para um trabalho de geografia. Em vez de olhar apenas os polos regionais recomendado pelo professor que solicitara o trabalho, o sindicalista me chamava atenção para a emergência de experiências políticoadministrativas.

O livro, na ocasião, além de me apresentar Lages (SC), permitiu-me refletir sobre a ideia de território e de comparar a experiência daquela localidade com a pobreza administrativa do meu município. As releituras vieram em diversas ocasiões: nos estudos de Graduação e de PósGraduação, na militância partidária, nos trabalhos no Instituto Polis, na candidatura a prefeito, na docência tanto na Escola de Sociologia e Política de São Paulo (FESPSP) quanto na Universidade de São Paulo (USP).

Com o tempo fui percebendo a importância de seu autor, Márcio Moreira Alves, do prefaciador Maurício 
Tragtemberg e do editor Caio Graco, cada qual merecedor de atenção e pesquisa especial.

Márcio Moreira Alves, jornalista, professor, deputado e escritor. Autor de quase duas dezenas de livros dos quais cinco volumes dedicados a relatar e analisar experiências de governos locais. Maurício Tragtemberg, por sua vez, professor da Unicamp, PUC-SP e da EAESPFGV, teórico importante no campo da análise as organizações e no campo da educação, além de articulista de diversos jornais, dentre os quais Notícias Populares e Folha de São Paulo. Finalmente, Caio Graco, importante editor e "agitador" cultural.

Então, vamos ao livro. Depois de praticamente 40 anos desde a publicação da primeira edição, que sentido faz apresenta-lo e sugerir a sua leitura?

Nas palavras de Tragtemberg (1980), A "Força do Povo" é antes de mais nada um relato "de práticas populares onde o povo tomou a palavra". Para o gestor público contemporâneo, a experiência de Lages é uma espécie de "grilo falante", consciência crítica que alerta para as possibilidades reais contra o marasmo e a mediocridade. Enquanto, atualmente, muitos gestores são meros executores de programas federais e estaduais, com baixa capacidade ou interesse em pensar a partir dos recursos disponíveis e dos problemas reais e específicos do território, a experiência de Lages foi exemplo antagônico de tal situação, contraponto aos projetos convencionais e às soluções mágicas que desde aquela época povoa a cabeça dos tecnocratas, áulicos e bajuladores de governantes das elites ideológicas, econômicas e políticas estaduais e federais.
O livro é composto pelo prefácio "A luz vem de Lages", de Maurício Tragtemberg, de um Anexo que compreende o "Código Tributário de Lages", da Introdução e de outros 10 capítulos. 0 livro não tem um capítulo de conclusão.

No primeiro capítulo, ao descrever a vista de uma placa de boas-vindas na estrada pouco antes de chegar ao município, há o que considero uma definição de território. Eis o que diz a placa: "Bem-vindo. Lages, a Força do Povo. Terra: $7.094 \mathrm{Km}^{2}$. Gente: 180.000". No cantinho da placa anuncia-se também: "Equipe Dirceu Carneiro".

Assim, indica uma base geográfica, física, espacial; gente; e instituições a partir da qual se constroem e se manifestam as relações de poder.

No segundo capítulo, há o que se chamaria no futuro de reforma administrativa. Neste caso, o centro da ação foi a política salarial: o leque salarial que distancia o funcionário menos aquinhoado do mais bem remunerado é de 1 para 10. Além disso, benefícios e gratificações, anteriormente, disponíveis somente para os servidores "estatutários" foram expandidos para os contratados pela Consolidação da Leis Trabalhistas (CLT). Retirados os detalhes, o que fica de lição é a possibilidade de reduzir as desigualdades por meio de política salarial. Ainda neste capítulo, o autor apresenta o processo eleitoral dos "intendentes distritais", uma espécie de subprefeitos eleitos pelas comunidades e nomeados pelo Prefeito. Trata também dos Conselhos de Escola, bem como dos Núcleos Agrícolas, e das Associações de Moradores e suas relações com o poder público municipal. 
No capítulo três é detalhado o processo de mutirão para a construção de 690 casas; o banco de materiais; a olaria comunitária para a produção de tijolos; o apoio de engenharia e arquitetura da prefeitura aos "mutirantes"; bem como o processo de produção das ruas e a implantação da infraestrutura de saneamento básico.

Nos capítulos quatro e cinco há uma série de descrições e análises de políticas diversas. Enfatizo o uso das tecnologias apropriadas na produção agrícola urbana e rural por um lado e o aproveitamento dos resíduos como composto, adubo e fertilizante, configurando o que se chama atualmente de economia circular.

Os capítulos seis e sete apresentam iniciativas nos campos da saúde, educação, promoção social e cultura. Os dois capítulos seguintes tratam de economia e política, ainda que essas questões permeiem o livro inteiro. Se algo merece destaque nesses capítulos é o compromisso da gestão em fazer política redistributiva também por meio de um Código Tributário Local em que se exige a atualização da Planta Genérica de Valores, a correção dos valores venais dos imóveis (base para a tributação); e uma política orçamentária com gastos controlados e investimentos intensivos nos bairros mais pobres e na área rural.

No último capítulo são apresentadas Leis de caráter popular e democrático como inspiração para os gestores daquela época e, com suas devidas adaptações, ponta de lança para debates contemporâneos.

Revejo a experiência de Lages sob dois aspectos: a criatividade com que o prefeito Dirceu Carneiro combinava recursos disponíveis e resolvia problemas com simplicidade; e a tecnologia usada ou desenvolvida pela equipe daquela gestão.

A equipe de Dirceu Carneiro era criativa. Enxergava entraves e problemas como oportunidades. Isso só era possível porque a equipe antes de mais nada era orientada pelo efetivo princípio da democracia participativa e trabalhava de forma integrada, articulada, era atualizada, trocava informações, ouvia o povo e as lideranças comunitárias e promovia o debate e a participação. Era uma equipe integrada para dentro da gestão, para dentro do território, e também para fora, buscando conhecimento e experiências no país e no exterior. Assim, geralmente "alguém" encontrava a solução para um problema que os burocratas achavam insolúvel.

Sobre o uso da tecnologia, a equipe fez uso intensivo da mão-de-obra, da terra, dos recursos naturais e dos fatores de produção disponíveis no território bem como de técnicas construtivas e organizacionais como a autogestão e o mutirão. Nesta perspectiva, tecnologia não era vista apenas como um artefato, mas também como técnica e ferramentas diversas.

O calçamento das ruas era feito de lajota para fugir da dependência do petróleo. 0 projeto de habitação possuía um "Banco de Materiais". As casas eram construídas em regime de mutirão, com tijolos, telhas e madeiras oriundas de demolições urbanas. A "argila era transformada em tijolo e telhas numa olaria experimental da Prefeitura, movida a gasogênio" e "as pedras e tijolos eram assentados sobre argamassa de argila, como faziam os antigos", fugindo-se assim 
da dependência e do alto custo do cimento e das empreiteiras. Em Lages, redescobriuse a cultura de legumes e frutas em fundos de quintal, e nas escolas foram feitas hortas, não apenas em sentido experimental. $\mathrm{O}$ adubo utilizado tanto nas escolas, quanto na agricultura familiar (com escala comercial) era orgânico, com capim picado e regado com bactérias compradas da indústria ecológica. A prefeitura criou uma fábrica de baterias, feitas artesanalmente, para armazenar energia. $\mathrm{Na}$ área de saúde, a partir da "consulta a curandeiros e pessoas entendidas na flora medicinal, foram produzidos chás e poções para combater lombrigas, baixar a febre, tratar dos rins e do fígado", como tecnologia e conhecimento cientificamente corretos e culturalmente adequados.

Por estes exemplos, seguindo a trilha de Maurício Tragtenberg, pode-se dizer que em Lages praticou-se "uma democracia participativa e uma economia ecológica". A experiência de Lages é, portanto, exemplo para repensar o uso racional dos recursos naturais, humanos e tecnológicos disponíveis no território, tornando cada município menos dependente das soluções economicamente caras, tecnologicamente inapropriadas e culturalmente subordinadas. Talvez o caminho de Lages esteja esquecido por falta de criatividade e pela arrogância das soluções complexas e burocráticas em detrimento das soluções singelos e da crença nas soluções caseiras.

\section{Referências Bibliográficas}

Alves, Márcio Moreira. (1980). A força do povo: democracia participativa em Lages. São Paulo: Editora Brasiliense.

Calvino, Ítalo. (1993). Por que ler os clássicos. São Paulo: Companhia das Letras.

Recebido em 14/03/2019. Aceito em 23/04/2019. 